\title{
Self-Assessment to Assess Student's Performance in Academic Task to Improve Metacognition
}

\author{
Siti Ina Savira, Hermien Laksmiwati
}

Universitas Negeri Surabaya, Surabaya, Indonesia

e-mail: sitisavira@,unesa.ac.id

\begin{abstract}
This study is aimed to examine whether self-assessment skill in dealing with academic task will improve learner's metacognition. The data collection method used was Metacognitive Awareness Inventory (MAI), interview, and retrospective think-aloud. Analysis is conducted using coding by data labeling or categorizing. The result of this study has shown that there is an increase in MAI score prior to and post intervention. It can be concluded that there is an increase in the learner's metacognitive awareness after selfassessment skill is taught.
\end{abstract}

Keywords: $\quad$ self-assessment, metacognition

\section{INTRODUCTION}

Metacognition has been studied and believed to be an important factor of human abilities, including students' success in learning $[1,2]$. It is argued that the difference in students' performance is more related to the degree of metacognitive awareness rather than personal factors such as intelligence $[2,3]$. The importance of metacognition is confirmed that the students with higher metacognition or metacognitive awareness are more likely to perform and use better strategies compare to less aware students [4]. Being metacognitively aware allows learners to make effective planning, adjustment and to monitor their learning process that directly aim to improve performance [5]. In alignment to that, selfregulation theory suggests that metacognition plays an important role that allows each phase of selfregulation (forethought, performance, and selfevaluation) to function and interact effectively [2,6].

Metacognition can be defined as 'the ability to reflect upon, understand, and control one's learning' $[3,5]$ or 'an awareness of and knowledge about one's thinking' [2]. Metacognition can be divided into two broad categories, knowledge of cognition and regulation of cognition. Knowledge of cognition consists of declarative knowledge (what strategies), procedural knowledge (how to use strategies), and conditional knowledge (when and why to use strategies). Regulation of cognition consists of 'planning, information management strategies, comprehension monitoring, debugging strategies, and evaluation' [3].

It is can be concluded, however, that the ability to monitor one's own learning is one important characteristic needed to be successful in learning [2]. Being able to assess one's own learning and understanding, for instance, is an important start to develop learner's critical thinking skill [7]. In selfregulation, it is the function of metacognition to continuously monitor and evaluate the effectiveness of cognitive strategy by comparing the initial learning objectives that have been set out with the result of the strategy applied. Therefore, teachers are required to explain explicitly and as clear as possible about learning objectives and 'success criteria' $[7,8]$. It is important that students are able to assess their current situation in learning; whether or not they have closed 'the gap between where they were and where they want to be' [9].

According to [2] proposed that the ability to set out a reasonable and achievable goal in learning may increase learner's self-efficacy because learners would then learn how to monitor even a subtle progress in their own learning. Learners may lose their motivation in learning when they cannot see any real progress in their learning [10]. Self-efficacy has been long believed to be one important factor in predicting learner's motivation and performance in learning $[11,12,13]$. 
Self-assessment is often suggested as a useful way to help a learner to actively engage and to take full responsibility for their own learning $[10,12,14]$. The role of self-assessment is that it helps the learner to stay active and focus on their learning by monitoring their own progress $[10,15]$. If learners positively evaluate their performance, they will be more likely to set higher goals and to commit themselves to put more effort in learning. Having the goals set and effort commitment will lead to better achievement, which will result in self-judgement [15]. A self-judgement element in self-assessment, allows the learner to be aware of what they know and what still needs to be learned [12], and thus, lead to self-reaction.

Furthermore, [14] argued that self-assessment is similar to 'regulatory process in metacognition'. Self-assessment can be defined as a process where students 'monitor and evaluate the quality of their thinking and behavior when learning and identify strategies that improve their understanding and skills'; that it is a cyclical process of 'selfmonitoring, self-judgement, and learning and instructional correctives' [12]. As [15] preferred the term self-evaluation, which defined as 'judging the quality of their own work, based on evidence and explicit criteria' in order to perform better in the future.

\section{METHOD}

\subsection{Research design}

The present study is a case study with a singlesubject design. The design is suggested to be appropriate particularly to investigate the effectiveness of an intervention in a particular subject or participant to identify individual factors [16].

\subsection{Participant}

The participant in this study was a single subject who is currently engaging in formal education that requires him/her to accomplish some academic tasks. The instructor approached the participant personally to ask his/her willingness to participate in the study. The participant was chosen based on convenient reasons, such as easy access, an established relationship, and the same cultural background to reduce risks in data collection, such as misinterpretation.

\subsection{Data collection and analysis}

There was two main data collecting method in this study, questionnaire, and interview. The questionnaire was MAI (Metacognitive Awareness Inventory) adapted from [3]. The full item of the questionnaire was available to free access, however, not the complete format. The instruction was formatted based on the description in the article that the purpose of the questionnaire was to assess knowledge about learning, that the result would not affect respondents' class grade in any way, and that it should be filled as carefully and truthfully as possible.

MAI has a reliability index of .90 and intercorrelation factors of .54. MAI consists of 52 items with 2 broad categories, knowledge and regulation of cognition, and 8 sub components, declarative knowledge (DK), procedural knowledge (PK), conditional knowledge (CK), planning (P), information management strategies (IMS), monitoring (M), debugging strategies (DS), and evaluation (E) [3].

A modification to the scale was made, however, to simplify the scoring process. [3] was using 100$\mathrm{mm}$ continuous scale, bipolar scale adapted from multidimensional scaling. They were arguing that the scale was more suitable for the purpose of the study compared to a Likert scale that it provides a better approximation to interval data and particularly, that it would increase response variance and thus, enhance the reliability of the instrument. In this study, being a single-subject study, the MAI score of the particular respondent would only be compared to her own post-intervention score to see whether any increase exists. Therefore, a 5 point Likert scale was used. The scale was also more appropriate for this present study because the response could be interpreted per item to allow deeper exploration on respondent's answer. It is not uncommon to analyze individual item on a Likerttype scale. For instance, the items where the participant chose the middle score gave a lot of opportunity for open questions that were used in the interview.

There was a problem in interpreting the middle point on the Likert scale, however, considering there was no pilot conducted. The initial Likert scale used was 'strongly agree' (5), 'agree' (4), 'neither agree' or 'disagree' (3), 'disagree' (2), and 'strongly disagree' (1). After given to the participant the response showed 19 items were at the middle score that means around $36 \%$ of the scale. The participant was then asked further about why she was unsure on those items, particularly to make sure that it was not because she could not understand the statements. Eliminating middle point is not suggested, since it may distort the result obtained from the scale [17]. The same article proposed that there is a tendency 
that respondent would lean toward the positive end when the middle point is eliminated due to social desirability bias or tendency to please. Therefore, in this study, the response in the middle point would be treated as an important data that may give deeper information regarding the participant, because the middle point in Likert scale is not the same as 'don't know' or 'no opinion' [18].

The items were all positive statements; therefore, the higher score means higher metacognitive awareness. The score could range between 52 to 260. It is not important, however, to create interval scores to classify metacognitive awareness of the participant in this study as low, moderate, or high. The purpose of the study was to examine whether a predicted increase as a result of applying a particular intervention could be confirmed. The latest version of the questionnaire as used in this study is attached in the appendix.

The second method of data collection was an interview. As mentioned briefly above, the interview was mostly based on the need to explore more on participant's response gathered from the questionnaire. Both questionnaire and interview were analyzed with coding since the nature of the study is a qualitative approach. The coding system for the questionnaire was using the codes used by [3]; DK, declarative knowledge; PK, procedural knowledge; CK, conditional knowledge; P, planning; IMS, information management strategies; $\mathrm{M}$, monitoring; DS, debugging strategies; and E, evaluation. The codes for data derived from the interview were KL, knowledge about learning; SE, self-efficacy; and MT, motivation.

\subsection{Procedure of intervention}

The intervention method in this study was teaching a self-assessment to assess learner's own performance in the academic task. [12] attempted to identify four stages of teaching student selfassessment to help teachers implement student selfassessment in the classroom (see Table 1). The idea of each stage is to gradually give students less direction and instruction. Self-assessment would be fully integrated into stages 3 and 4 [12].
Table 1. Growth scheme for teacher implementation of stages of student self-assessment

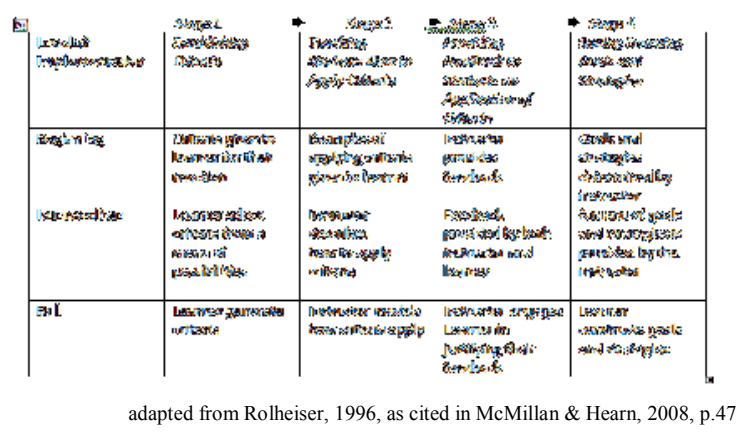

Furthermore, [15] provide practical guidance for teachers to teach self-assessment.

Table 2. Practical guideline to teach self-assessment

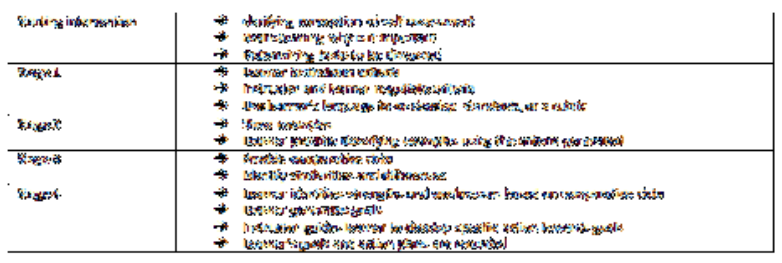

adapted from Rolheiser and Ross (2001) of sample of the 4-stage self-evaluation

However, considering the progress and the level of education of the participant, which basically had provided the subject with a lot of experience in accomplishing academic tasks, some of the levels and stages of the implementation were combined. For instance, the main difference between the two levels relies on the emphasis of the role of the instructor to provide direction and instruction. In this study, however, the instructor would immediately adjust her role by reflecting on participant's response as progressing in the intervention. Therefore, without neglecting the guidance provided in [15], the intervention did not follow the strict steps as suggested above.

\section{RESULT}

\subsection{MAI score prior to intervention.}

The summated MAI score of the participant prior to intervention was 185 with 19 items or equal to 57 points was at the middle point of the Likert scale. The 19 items were distributed almost equally to 8 sub components that constructed the scale. The 19 items were discussed with the participant. 


\subsection{Interview.}

A focus interview was conducted to support a qualitative analysis on each of 19 individual that scored 3 of MAI scale. From the focus interview, it was found that there were several reasons why the participant decided to answer with 'neither agree nor disagree'; the statements were not always true ('sometimes I do, sometimes I don't), 'not sure if it describes me' or 'I never really think about it', and that some of the statements were unclear. However, when the participant was asked why not chose to disagree instead, she argued that disagree means 'never'. The participant then suggested to changing the middle point into 'sometimes'. One of the items she found to be unclear was item \#41 that contains 'organizational structure of the text'. The instructor was then reviewing the items of which the participant found confusing and explained what they mean and have the participant to score each of the items again. The participant, however, did not make any changes in her initial response to the scale and insisted on having those items on middle point. From the information generated from the focus interview, and the fact that the over $36 \%$ item in the scale was on middle point and 2 items were scored 2 (disagree), the instructor then concluded that improving the participant's metacognitive awareness may be useful.

The participant, for instance, admitted that she does not necessarily set a specific goal to achieve prior to learning, does not always understand what the teacher expect from her, and that she is not always good in judging her own understanding, and disagree with the statement 'I know how well I did once I finish a test'. This seemed to lead to average performance, her essay usually marked Credit, or Pass, and it made her thinking that in general, writing an essay is just not something that she can do well. She claimed to have some strategies, such as constructing essay outline, ask friends when she finds something difficult, and try to make connections with her previous knowledge. However, terms of knowledge about learning or the metacognition, she admitted that she never thought about it. When she was asked to illustrate or describe the learning process the way she knows it, she describes it as teachers came with learning goals ('lecturers came to class, and explain what the topic about'), and construct assignment that will guide students to achieve that goal ('explain what we have to do to pass ..the requirement of the topic'; 'sometimes they explain the relationship between assignment and what we need to achieve in order to pass, for example, ability to analyse, to criticise, and so on'). When asked about the role of learners in learning, she explained that learners must understand what teachers expect from them, and every teacher could be very different in that term. Finally, she was asked to summarize what she knows about knowledge about learning. At first, she said 'I don't know', after the instructor encouraged her to try, she said, 'knowledge about what is learning, ... how to learn.. how to do it'. It is the limitation of this study, however, that it cannot provide deeper analysis on the individual items due to the scale and the nature of the study. Deeper exploration of each item response could provide valuable information about learner's metacognition.

\subsection{Starting the intervention.}

Like any other cognitive intervention, it is crucial to have the participant motivated and willing to learn. Therefore, the first thing to do before starting the intervention was to show the participant what the intervention was all about. [15] suggesting the importance of having the same perception on selfassessment, what it means, and why is it important. It is important to understand that self-assessment is more than just 'marking your own work'. Selfassessment was explained as 'judging the quality of your own work'. The instructor was then asked the participant to think of several reasons why this might be important. The participant came up with answers like 'so that we know how good our work is', 'to be able to predict the result/marking'. The instructor then explained further that self-assessment will allow us to monitor our own progress in learning, to evaluate whether we have reached our goal in learning and that by having that information about our own learning, we would be more likely to engage and motivated in our own learning. The instructor and participant then discussed what kind of task that will be used for applying selfassessment. The task chosen was writing an essay based on the focus question that was given as a requirement of the task. It is important to note, however, that ideally self-assessment is taught by the teacher so that the criteria could be negotiated directly between the teachers and the students. Although the focus question of the task could have described the success criteria, it could probably affect participant's perception of how effective the intervention was, which may, in turn, compromise the effectiveness of the whole process. 


\subsection{Beginning and Intermediate Level of Implementation of Self-Assessment.}

Stage 1. The first stage in teaching self-assessment is establishing criteria. First, instructor studied the focus question of the essay that the participant had already submitted but still waiting for feedback. From the focus question, the instructor then tried to establish criteria of success that were explicitly provided. For instance, not repeating the same three or four articles throughout the essay or footnotes that made them looked like the main resources, set your perimeter to limit your discussion, use your own words in reflecting what you have read, use at least two final paragraph for a conclusion, and so on. The essay description also provided several questions that the students need to think about when writing their essay. It is also important to note that not all focus questions are as clear and descriptive as that. Some teachers may prefer to discuss assignments in more detail verbally in a class where students may discuss and ask direct questions regarding a particular task.

Both the instructor and the participant then discussed the essay based on the criteria. It was interesting that while reviewing the criteria, particularly the questions that were provided as guidelines to construct the essay, the participant was almost instantly recognized the weaknesses in her essay. For instance, she almost immediately said that her essay failed to answer "why you feel disappointed in the depth of analysis being offered from the resources that you read?' She described her essay as description and retelling of the readings instead of analyzing them. However, when asked whether she had thought about this before, the participant said no.

Stage 2 and 3. In this stage, the instructor is teaching the participant how to apply criteria and provide feedback to the participant. After having to review her own essay, the participant had recognized some of the weaknesses in her essay. The instructor then showed her an example of a marked essay that received good feedback. The instructor asked her to compare, particularly the introduction section, how was it different from hers. She then concluded that the better essay had briefer and straightforward introduction. The instructor then added that an introduction is a good place to 'set your perimeter' and 'limit the discussion in your essay', which was part of the criteria of success as described in the focus question. Therefore, the lack of depth of her essay could be easily noticed from her introduction.

\subsection{Full Level of Implementing Self- assessment.}

Stage 1 and 2. With different task, the instructor and the participant tried to repeat the process above of implementing self-assessment. The second assignment was also had been submitted but not yet returned. This time the participant was asked to establish her own criteria based on the description provided in the essay description and then tried to apply the criteria on the essay. At the end of the intervention, when reviewing her own essay using her own criteria, the participant also seemed to be more confident that she understands how to set up criteria to evaluate her essay. She would say 'I can see how I can revise my essay now'.

MAI score post-intervention. The summated score of MAI scale after an intervention was 191, which was 6 points higher than the one prior to intervention. There were 6 of a 1 point increase on items \#6 (I think about what I really need to learn before I begin a task), \#8 (I set a specific goals before I begin a task), \#10 (I know what kind of information is most important to learn), \#16 (I know what the teacher expects me to learn), \#19 (I ask myself if there was an easier way to do things after I finish a task), and \#47 (I try to break studying into smaller steps), from 'neither agree nor disagree' to 'agree'.

Interview. When asked about the items on the middle point of the scale, the participant still thought that she was not sure with some of the statements in the questionnaire.

\section{DISCUSSION}

Based on the comparison between MAI score prior to and post intervention, it can be seen that there was an increase in MAI score of the participant after the intervention self-assessment was given. It was interesting to note that the items where there was an increase mostly related to setting initial goal and understanding what teachers expect from the learners. Compare to the initial state of the participant, where she would describe learning process as mainly directed and elaborated by the teachers, this change shows some understanding of the importance of having a personal goal(s) in learning. This also suggests that self-assessment is a skill that requires practice and that it is difficult to master with several sessions of intervention. The literature on self-assessment would suggest that teaching self-assessment could be started by practicing peer-assessment $[14,12]$ or teaching it in a group so the students are able to compare their criteria with their peers [15]. 
Self-assessment does seem to encourage learners to activate their metacognition since, in order to self-assess or to judge the quality of one's own work, the learner has to continuously make a comparison between the desired state and the current state of their learning. This implies the metacognitive functioning of planning, judging, and monitoring [5], which may also be applied within the cycle of self-regulation that involves forethought, performance, and reflection [2]. Recognizing this gap with a clear 'standard and criteria' [12] would also encourage the learner to put more effort to accomplish the task because the standard and criteria serve as guidelines for them to improve and perform better in the future.

In term of self-assessment as a monitoring device and that it improves metacognitive awareness as assumed earlier in this study an alternate explanation may be suggested. It is suggested from this present study that understanding self-assessment as a cycle of self-monitoring, self-judgement, and learning target and instructional correctives [12] means that teachers and learners must understand the possibility that the consequence of acquiring this skill could be quite profound because selfassessment is a complex process. For instance, when the learner is able to monitor the weaknesses in his/her learning they would likely to immediately adjust or correct their learning.

Acquiring self-assessment skill seems to have 'snow ball effect' on learner's general learning skill. It can be seen that on the first trial of applying 4stage self-assessment model, the participant seemed to immediately recognize her essay weakness based on the established criteria. This finding should encourage teachers to make sure that have provided clear guidelines to assist students in establishing criteria needed to guide them to successfully accomplish a task. It also confirms that with a clear standard and criteria learners would be more likely to put more effort or to be more motivated to engage in learning. When the goal is reasonably achievable learner's self-efficacy would likely to increase and it may encourage them to perform better in learning [2].

It was part of controversy presented in the literature review of this present study whether the relationship between monitoring accuracy and metacognitive awareness is domain-specific in nature. it is not the nature of this study to be able to answer that question since there is no comparison made. [15] however, suggest that self-assessment or self-evaluation do have a significant effect on students writing skill. In this study, the finding indicates that self-assessment may have a general effect on learners' skill in learning. As mentioned earlier, the fact that self-assessment may affect learner's metacognitive awareness is not merely because of its monitoring function, but rather the complexity of the process. Therefore, it is difficult to isolate the effect of monitoring function in selfassessment to metacognitive awareness.

Assuming that self-assessment would serve as a monitoring skill has proven to be a simplification of a complex process. The amount of potential data that could be derived from individual analysis of MAI scale could not be fully explored. Further study to investigate and explore the process of selfassessment in relation to metacognitive awareness would be valuable.

Many literature and previous research would confirm the relationship between self-assessment, metacognition, and self-regulation; however, the scope of the topic could not be covered in this study. It would be interesting to further investigate the dynamic or relationship of some parts or components of each of them.

The participant in this study, however, was an adult learning studying tertiary education. This implies her experience in accomplishing an academic task. It is possible that personal factor such as maturity had helped to promote the acquisition of self-assessment skill. Enriching the analysis of this present study with personal factors theory, such as maturation, to investigate how such factor may affect the acquisition of self-assessment.

\section{REFERENCES}

[1] R.J. Sternberg, "Metacognition, abilities, and developing expertise: What makes an expert student?" Instructional Science, vol. 26, 1998, pp. 127-140.

[2] B.J. Zimmerman, Becoming a self-regulated learner. Theory into Practice, vol. 41, 2002, pp. 64-70.

[3] G. Schraw and R.S. Dennison, "Assessing metacognitive awareness", Contemporary educational psychology, vol.19, 1994, pp. 460475 .

[4] R. Garner and P.A. Alexander, "Metacognition: Answered and unanswered questions" Educational Psychologists, 24, 1989, pp. 143158.

[5] G. Schraw, "Promoting general metacognitive awareness". Instructional Science, vol. 26, 1998, pp.113-125. 
[6] B.J. Zimmerman, "Theories of Self-regulated learning and academic achievement: An overview and analysis", in B. J. Zimmerman \& D. H. Schunk (Eds.), Self-Regulated Learning and Academic Achievement: Theoretical Perspectives, Mahwah, New Jersey: Lawrence Erlbaum Associates, Publishers, 2001, pp. 1-37

[7] L.E. Young, "Critical thinking skills: Definitions, implications for implementation", NASSP Bulletin, vol. 76, issue 47, 1992, doi: 10.1177/019263659207654806

[8] M.R. Clerkin, "How can I use Irish language eportfolios in the assessment for learning approach in my primary classroom?" Educational Journal of Living Theories, vol. 2, issue 1, 2009, pp. 32-67.

[9] L.E. Young, Assessment for learning:

Embedding and extending, 2005, [online article], retrieved from

http://www.ltscotland.org.uk/Images/Assessmen $\mathrm{t} \% 20$ for $\% 20$ Learning $\% 20$ version $\% 202 \mathrm{vp}$ tcm 4 -385008.pdf

[10] M. Harris, "Self-assessment" ELT Journal vol. 51, January 1997.

[11] A. Bandura, "Perceived self-efficacy in cognitive development and functioning", Educational Psychologist, 28, issue 2, 1993, pp.117-148.

[12] J.H. McMillan and J. Hearn, Student selfassessment: The key to stronger motivation and higher achievement. Educational Horizon, 2008.

[13] B.J. Zimmerman, "Self-Efficacy: An Essential Motive to Learn", Contemporary Educational Psychology", vol. 25, 2000, pp. 82-91, doi: 10.1006/ceps.1999.1016

[14] L. Earl, Assessment as learning: using classroom assessment to maximise student learning. Thousand Oaks, CA: Corwin Press, 2003

[15] C. Rolheiser and J.A. Ross, "Student selfevaluation: What research says and what practice shows", [online article], retrieved from http://www.cdl.org/resourcelibrary/articles/self_eval.php?type $=$ subject\&id= 4, 2001

[16] M.V. Johnston and R.O. Smith, "Single subject designs: current methodologies and future directions". OTJR: Occupation, Participation, and Health, vol. 30, Winter, 2010, pp. 4-10.

[17] G. Albaum, "The Likert scale revisited: an alternate version", Journal of the Market Research Society vol. 39, issue 2, 1997, pp. 331-348.

[18] R. Garland, "The mid-point on a rating scale: is it desirable?" Marketing Bulletin, vol. 2, May 1991, pp. 66-70.G. Albaum, "The Likert scale revisited: an alternate version", Journal of the Market Research Society vol. 39, isuue 2, 1997 , pp. 331-348. 